\title{
PENGARUH PERCEIVED SECURITY DAN INFORMATION QUALITY TERHADAP TRUST SERTA DAMPAKNYA TERHADAP ONLINE PURCHASE INTENTION
}

\section{Selfi Dayanti, Ida Bagus Nyoman Udayana, Bernadetta Diansepti Maharani}

Fakultas Ekonomi Universitas Sarjanawiyata Tamansiswa (UST) Yogyakarta, Indonesia Email: selfidayanti2804@gmail.com,ibn_udayana@yahoo.co.id, bernadettadian@ustjogja.ac.id

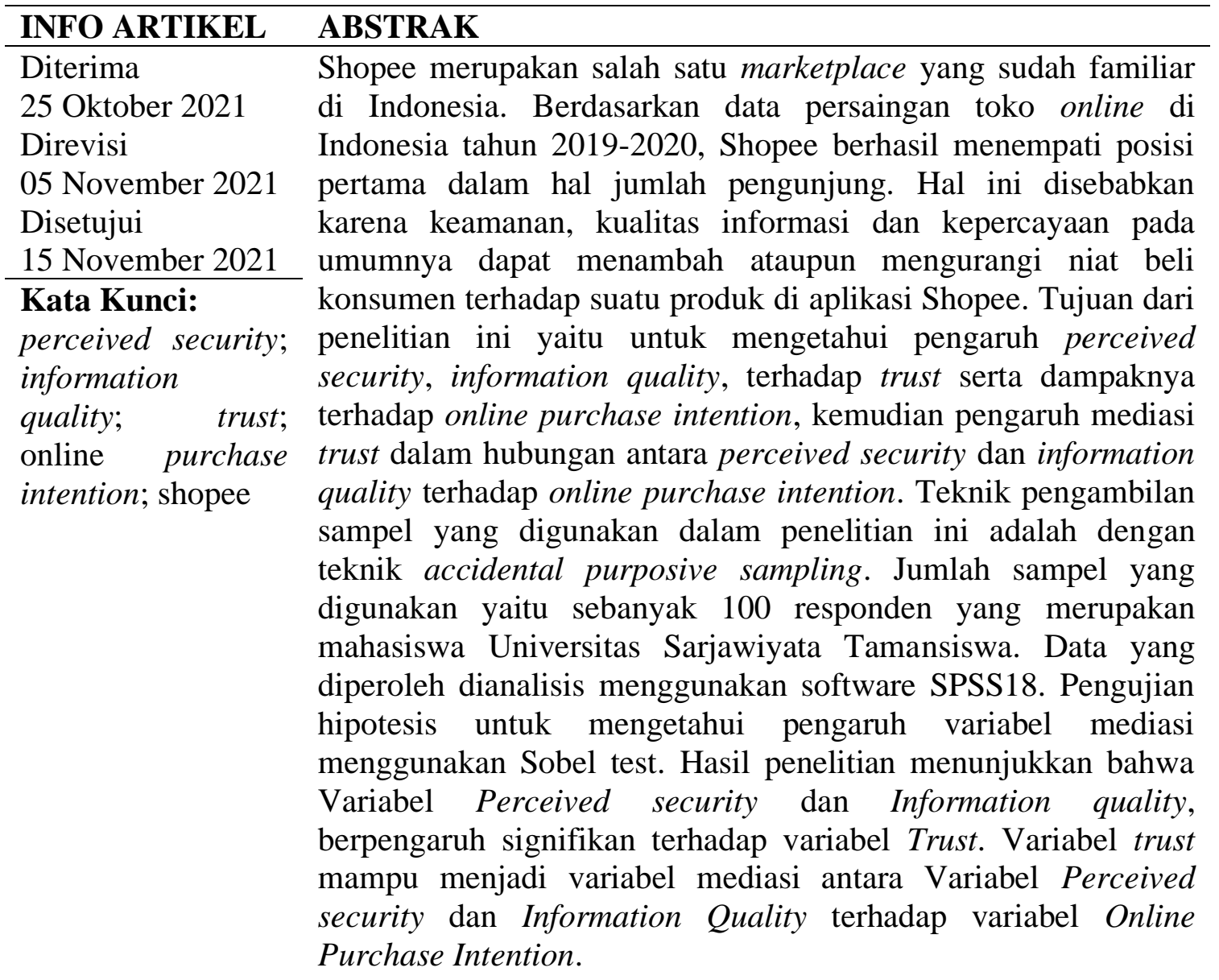

\section{ABSTRACT}

Shopee is one of the most familiar marketplaces in Indonesia. Based on online store competition data in Indonesia for 2019. 2020, Shopee managed to occupy the first position in terms of the number of visitors. This is because security, quality of information and trust in general can increase or decrease consumer buying intentions for a product in the Shopee application. The purpose of this study is to determine the effect of perceived security, information quality, on trust and its impact

How to cite:

E-ISSN:

Published by:
Dayanti, S., Ida Bagus Nyoman Udayana, \& Bernadetta Diansepti Maharani. (2021) Pengaruh Perceived Security dan Information Quality Terhadap Trust Serta Dampaknya Terhadap Online Purchase Intention. Jurnal Syntax Admiration 2(11). https://doi.org/10.46799/jsa.v2i11.335 2722-5356

Ridwan Institute 
on online purchase intention, then the influence of trust mediation in the relationship between perceived security and information quality on online purchase intention. The sampling technique used in this research is the accidental purposive sampling technique. The number of samples used are 100 respondents who are students of the University of Sarjawiyata Tamansiswa. The data obtained were analyzed using SPSS18 software. Hypothesis testing to determine the effect of the

Keywords:

perceived security; information quality; trust; online purchase intention; shopee mediating variable using the Sobel test. The results showed that the variables of Perceived security and Information quality had a significant effect on the Trust variable. The trust variable is able to be a mediating variable between the Perceived security and Information Quality variables on the Online Purchase Intention variable.

\section{Pendahuluan}

Jual beli barang secara online sangat disukai oleh orang kebanyakan karena dirasa lebih efektif dan praktis. Bagaimana tidak, penjual tidak perlu lagi mendirikan toko fisik untuk menjual dagangannya dan pembeli tidak perlu repot pergi ke toko atau ke pasar untuk mendapatkan barang yang dibutuhkan. Cukup duduk santai sambil mengetuk layar ponsel dalam waktu singkat, barang yang dibeli sudah diantar ke pemesan. Meskipun demikian jual beli online juga memiliki kekurangan, salah satunya pembeli tidak dapat mengetahui keadaan barang yang dibeli sebelum barang diterima.

Jual beli online dianggap menciptakan peluang yang sangat besar bagi perekonomian. Tidak menyia-nyiakan peluang tersebut, banyak perusahaan yang mendirikan toko online atau marketplace untuk mencari keuntungan. Toko online tersebut antara lain Lazada, Tokopedia, Shopee, Zalora, Blibli dan masih banyak lagi yang masing-masing memiliki caranya sendiri untuk menarik pembeli.

Shopee merupakan salah satu marketplace yang sudah familiar dan perkembangannya cukup pesat di Indonesia. Selain barang yang dijual beraneka ragam, Shopee juga memberikan promo yang melimpah. Berbagai inovasi yang dilakukan telah banyak menarik minat pembeli untuk membeli barang di Shopee.

Berikut adalah gambar yang menunjukan pemain besar marketplace berdasarkan rata-rata pengunjung website di setiap kuartal pada tahun 2019. 
Gambar 1

Data Persaingan Toko Online Indonesia Tahun 2019-2020

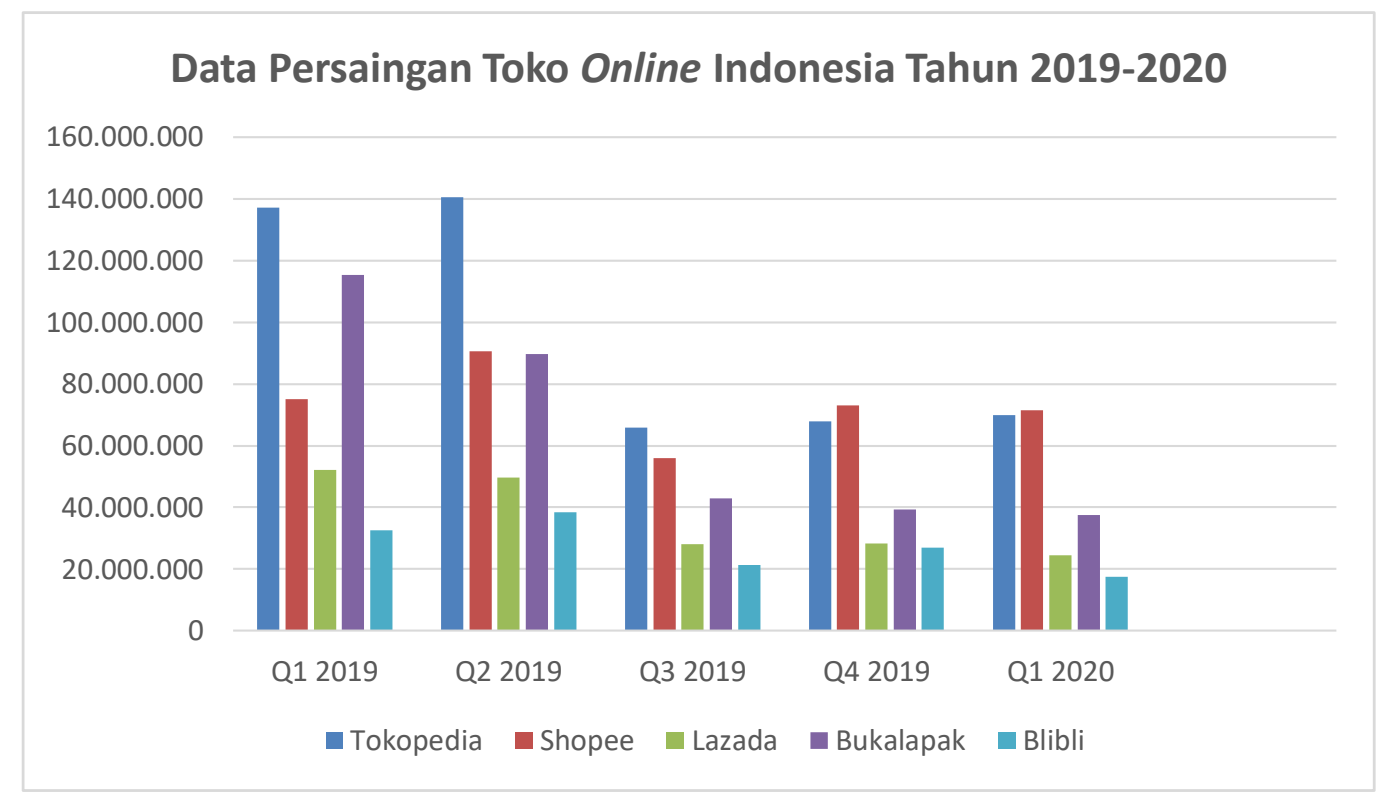

Sumber: https://iprice.co.id/insights/mapofecommerce/

Gambar 1 menunjukkan data persaingan toko online pada tahun 2019 hingga kuartal 1 tahun 2020. Meskipun sejak kuartal 4 tahun 2019 Shopee mampu menempati posisi pertama dalam persaingan toko online di Indonesia, namun terjadi penurunan jumlah pengunjung pada kuartal berikutnya. Hal tersebut menunjukkan bahwa Shopee masih belum mampu mempertahankan pembeli untuk dating ke tokonya. Walau demikian Shopee harus tetap bertahan dan mampu menghadapi tekanan dari kompetitornya.

Sebagai strategi bersaing, Shopee harus bisa menciptakan rasa aman kepada pembeli dalam melakukan pembelian barang, dalam hal ini baik barang yang dibeli, proses pengiriman barang maupun setelah pembelian barang. Rasa aman yang dirasakan dalam pembelian barang ini disebut perceived security. Fahmi \& Evanita, (2019) mengutip dari Arpaci (2015) menyatakan Perceived Security adalah derajat keyakinan seseorang bahwa teknologi yang digunakan untuk mengirimkan informasi yang sensitif seperti data konsumen dan data transaksi finansial terjamin keamananya. Menurut Escobar-Rodríguez \& Bonsón-Fernández (2017) terlepas dari investasi besar dalam teknologi keamanan, seperti segel privasi, mekanisme otentikasi, dan enkripsi, ada ambiguitas mengenai apakah investasi ini memiliki pengaruh terhadap persepsi pelanggan online tentang privasi dan keamanan.

Sebagai media pemasaran yang terbilang baru, E-commerce mengandung risiko yang lebih besar dibandingkan dengan pembelian secara konvensional. Hal ini dikarenakan pada saat transaksi berlangsung antara penjual dan pembeli tidak saling bertemu. Kejahatan secara online pun tidak dapat dihindari, namun shopee menawarkan keamanan dalam transaksi yang terjadi di aplikasi shopee. Dengan adanya jaminan keamanan yang diberikan, diharapkan pengguna shopee dapat melakukan transaksi 
secara lebih aman dan tidak khawatir oleh adanya penipuan pada saat transaksi tersebut (Alwafi \& Magnadi, 2016).

Selain menciptakan rasa aman, Shopee juga harus memberikan informasi terhadap pelanggannya. Informasi yang diberikan sangat berdampak bagi pelanggan dalam mengambil keputusan pembelian barang. Maka dari itu kualitas informasi harus sangat diperhatikan. Informasi yang baik adalah informasi yang dapat membuat pendengarnya paham dan tertarik dengan informasi tersebut. Informasi tentang promo dan karakteristik barang adalah salah satu hal yang harus diperhatikan, itu dikarenakan pelanggan sangat tertarik akan kedua hal tersebut.

Menurut Dewi \& Dwirandra, (2013) kualitas informasi ialah suatu karakteristik dari suatu informasi demi memenuhi kebutuhan individu saat dibutuhkan. Hall (2007:19) menyebutkan pembuatan informasi merupakan proses menyusun, mengatur, memformat dan menyajikan informasi kepada pengguna. Widarsono, (2007) mengutip dari Leitch, et al (1992) menyatakan informasi yang dihasilkan suatu sistem informasi merupakan sumber daya bagi organisasi, dimana informasi tersebut dapat mendukung manajemen dalam pengambilan keputusan. Demikian juga Romney et.al, (1992 :14) menyatakan bahwa manfaat utama dari informasi adalah mengurangi ketidakpastian, mendukung keputusan, dan mendorong lebih baik dalam hal perencanaan dan penjadwalan aktivitas kerja.

Memberikan informasi yang berkualitas dan rasa aman kepada pembeli, maka dengan sendirinya akan timbul rasa percaya atau trust yang dirasakan oleh pembeli terhadap aplikasi Shopee. Para peneliti telah mendefinisikan kepercayaan dalam berbagai cara. Menurut Escobar-Rodríguez \& Bonsón-Fernández, (2017) dikutip dari Rousseau et al. (1998) mendefinisikan kepercayaan sebagai keadaan psikologis terdiri dari niat untuk menerima kerentanan berdasarkan harapan positif niat atau perilaku orang lain. Sedangkan menurut Parastanti, Kumadji, \& Hidayat, (2014) kepercayaan adalah keyakinan pihak tertentu terhadap yang lain dalam melakukan hubungan transaksi berdasarkan suatu keyakinan bahwa orang yang dipercayainya akan memenuhi segala kewajibannya secara baik dan sesuai dengan yang diharapkan.

Halim, (2015) menyatakan rasa percaya atau tidak percaya seseorang yang muncul dalam perilakunya ditentukan oleh faktor-faktor seperti informasi, pengaruh, dan pengendalian. Kepercayaan akan meningkat bila informasi yang diterima dinilai akurat, relevan, dan lengkap. Setelah konsumen mendapatkan apa yang dibutuhkan seperti keamanan dan informasi hingga menimbulkan kepercayaan yang dirasakan, maka akan timbul purchase intention atau niat pembelian barang oleh konsumen di aplikasi Shopee. Menurut Parastanti, Kumadji, \& Hidayat, (2014) purchase intention adalah intensi seseorang untuk membeli merek tertentu yang mereka pilih sendiri setelah melalui berbagai evaluasi.

Online purchase Intention merupakan situasi dimana konsumen berkeinginan dan berniat untuk membuat transaksi online. Sedangkan menurut Semuel \& Setiawan, (2018) purchase intenion adalah kondisi dimana konsumen berniat untuk membeli suatu produk sepatu olahraga. Dalam proses minat beli seorang konsumen melakukan 
evaluasi terlebih dahulu sebelum melakukan pembelian. Seorang konsumen tidak akan langsung melakukan proses pembelian mereka akan melakukan evaluasi seperti memilih toko yang akan di kunjungi, kapan untuk membeli, dan hal-hal lainnya Semuel \& Setiawan, (2018).

Berdasarkan uraian di atas, kepercayaan (trust) terhadap aplikasi Shopee sangat ditentukan oleh beberapa faktor, seperti perceived security dan information quality. Tujuan penelitian ini adalah untuk mengetahui pengaruh perceived security dan information quality terhadap trust serta dampaknya terhadap online purchase intention pada mahasiswa Universitas Sarjanawiyata Tamansiswa pengguna aplikasi Shopee.

\section{Metode Penelitian}

Penelitian ini bersifat kuantitatif. Populasi yang tercakup dari penelitian ini adalah mahasiswa Universitas Sarjanawiyata Tamansiswa yang menggunakan aplikasi Shopee. Sampel penelitian adalah 100 responden. Teknik pengambilan sampel yang digunakan dalam penelitian ini adalah dengan teknik accidental purposive sampling. Accidental purposive sampling adalah pengambilan sampel berdasarkan kebetulan dapat ditemukan seketika itu namun harus sesuai dengan kriteria yang telah ditentukan (Sugiyono, 2015).

Sumber data dalam penelitian ini adalah mahasiswa Universitas Sarjanawiyata Tamansiswa yang menggunakan aplikasi Shopee. Metode pengumpulan data pada penelitian ini adalah menggunakan metode angket atau kuesioner. Teknik analisis data menggunakan analisis regresi ganda dan sobel tes.

\section{Hasil dan Pembahasan}

\section{A. Hasil Penelitian}

1. Perceived Security (X1) dan Information Quality (X2) Terhadap Trust (Z)

Tabel 1

Perceived Security (X1) dan Information Quality

(X2) Terhadap Trust (Z)

Coefficients $^{a}$

\begin{tabular}{cccccc}
\hline Model & \multicolumn{2}{c}{$\begin{array}{c}\text { Unstandardized } \\
\text { Coefficients }\end{array}$} & $\begin{array}{c}\text { Standardized } \\
\text { Coefficients }\end{array}$ & & \\
& $\mathbf{B}$ & Std. Error & Beta & t & Sig. \\
\hline 1 (Constant) & 4.696 & .929 & & 5.054 & $\mathbf{. 0 0 0}$ \\
\hline P. Security & .296 & .067 & .390 & 4.403 & .000 \\
\hline I. Quality & .316 & .082 & .342 & 3.856 & .000 \\
\hline
\end{tabular}

a. Dependent Variable: Trust

Sumber : Data primer diolah, 2020

Pengujian pengaruh Perceived Security (X1) terhadap Trust (Z) diperoleh nilai signifikan $0,000<0,05$ atau 4,403 (t-hitung) $>1,9847$ (t-tabel), maka dapat disimpulkan bahwa Perceived Security berpengaruh signifikan terhadap Trust. Artinya, semakin baik Perceived Security maka semakin tinggi pula Trust konsumen terhadap penggunaan aplikasi Shopee, sebaliknya semakin rendah 
Perceived Security maka semakin rendah pula Trust konsumen terhadap penggunaan aplikasi Shopee.

H1 Yang Menyebutkan Perceived Security Berpengaruh Terhadap Trust Diterima.

Pengujian pengaruh Information Quality (X2) terhadap Trust (Z) diperoleh nilai signifikan $0,000<0,05$ atau 3,856 (t-hitung) $>1,9847$ (t-tabel), maka dapat disimpulkan bahwa Information Quality berpengaruh signifikan terhadap Trust. Artinya, semakin baik Information Quality makan semakin tinggi Trust konsumen terhadal penggunaan aplikasi Shopee, sebaliknya semakin rendah Information Quality maka semakin rendah pula Trust konsumen terhadap aplikasi Shopee.

H2 Yang Menyebutkan Information Quality Berpengaruh Terhadap Trust Diterima.

2. Perceived Security (X1) Information Quality (X2) dan Trust (Z) Terhadap Online Purchase Intention (Y)

Tabel 2

Perceived Security (X1) Information Quality (X2) dan Trust (Z) Terhadap Online Purchase Intention (Y) Coefficients $^{a}$

\begin{tabular}{cccccc}
\hline \multirow{2}{*}{ Model } & \multicolumn{2}{c}{$\begin{array}{c}\text { Unstandardized } \\
\text { Coefficients }\end{array}$} & $\begin{array}{c}\text { Standardized } \\
\text { Coefficients }\end{array}$ & & \\
\cline { 2 - 4 } & $\mathbf{B}$ & Std. Error & Beta & t & Sig. \\
\hline 1 (Constant) & 3.386 & 1.418 & & -2.388 & .019 \\
P.Security & .245 & .100 & .231 & 2.453 & .016 \\
I.Quality & .270 & .119 & .209 & 2.263 & .026 \\
Trust & .493 & .137 & .353 & 3.595 & .001 \\
\hline
\end{tabular}

a. Dependent Variable: Online Purchase Intention Sumber : Data primer diolah, 2020

Pengujian pengaruh Perceived Security (X1) terhadap Online Purchase Intention (Y) diperoleh nilai signifikan 0,016 < 0,05 atau 2,453 (t-hitung) > 1,9847 (t-tabel), maka dapat disimpulkan bahwa Perceived Security berpengaruh signifikan terhadap Online Purchase Intention.

H3 Yang Menyebutkan Perceived Security Berpengaruh Terhadap Online Purchase Intention Diterima.

Pengujian pengaruh Information Quality (X2) terhadap Online Purchase Intention (Y) diperoleh nilai signifikan 0,026 <0,05 atau 2,263 (t-hitung) > 1,9847 (t-tabel), maka dapat disimpulkan bahwa Information Quality berpengaruh signifikan terhadap Online Purchase Intention.

H4 Yang Menyebutkan Information Quality Berpengaruh Terhadap Online Purchase Intention Diterima.

Pengujian pengaruh Trust $(\mathrm{Z})$ terhadap Online Purchase Intention (Y) diperoleh nilai signifikan 0,001 <0,05 atau 3,595 (t-hitung) > 1,9847 (t-tabel), maka dapat disimpulkan bahwa Trust berpengaruh signifikan terhadap Online Purchase Intention. 
H5 Yang Menyebutkan Trust Berpengaruh Terhadap Online Purchase Intention Diterima.

\begin{tabular}{ccccc}
\multicolumn{5}{c}{ Tabel 3 } \\
Hasil Uji Adjusted R Square \\
Model Summary
\end{tabular}

a. Predictors: (Constant), trust - Kepercayaan (1), Informational quality - kualitas informasi (X2), Perceived Security - Keamanan (X1),

Koefisien determinasi menunjukkan tingkat kemampuan masing-masing nilai variabel independen dalam menjelaskan variasi nilai variabel dependen, yang dinyatakan dengan persentase. Dari tabel 3 di atas diperoleh nilai Adjusted $R$ square sebesar 0,413 atau koefisien determinasi sebesar 0,413 x 100\% $=41,3 \%$, artinya variasi nilai variabel dependen (Online Purchase Intention) mampu dijelaskan oleh variasi nilai variabel independen (Perceived Security, Information Quality dan Trust), sedangkan sisanya sebesar 58,7\% (100\% - 41,3\%) variasi nilai variabel Online Purchase Intention mampu dijelaskan oleh variabel - variabel lain yang tidak dimasukan dalam model penelitian ini.

Pada standardized beta coefficient dengan variabel dependent Trust, maka dapat diketahui bahwa variabel Perceived Security memiliki pengaruh yang dominan terhadap variabel Trust dengan nilai $\alpha$ sebesar 0,390 diikuti variabel Information Quality dengan nilai $\alpha$ sebesar 0,342 .

Pada standardized beta coefficient dengan variabel dependent Online Purchase Intention, maka dapat diketahui bahwa variabel Trust memiliki pengaruh yang dominan terhadap variabel Online Purchase Intention dengan nilai $\alpha$ sebesar 0,353 diikuti variabel Perceived Security dengan nilai $\alpha$ sebesar 0,231 dan variabel Information Quality dengan nilai $\alpha$ sebesar 0,209.

\section{Sobel Test}

a) Perceived Security Terhadap Online Purchase Intention Melalui Trust

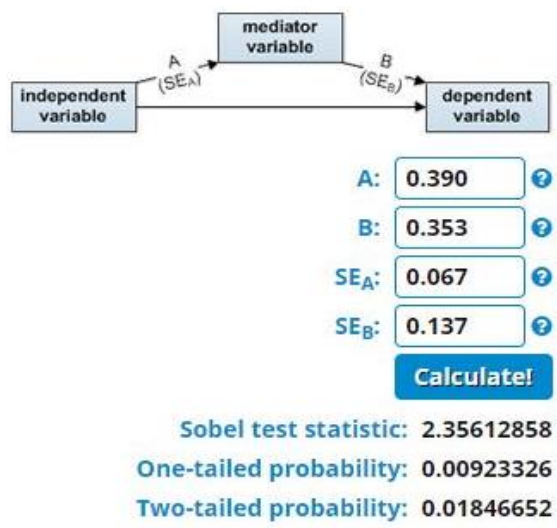

Gambar 1

Pengaruh Tidak Langsung Perceived Security

Sumber : Data Primer Diolah, 2020 
Dari hasil perhitungan sobel test di atas mendapatkan nilai sobel test sebesar 2,356, karena nilai sobel test yang diperoleh sebesar 2, 356>1,9847 (ttabel) maka dapat diambil kesimpulan bahwa Trust mampu menjadi variabel mediasi antara Perceived Security dan Online Purchase Intention.

b) Information Quality Terhadap Online Purchase Intention Melalui Trust

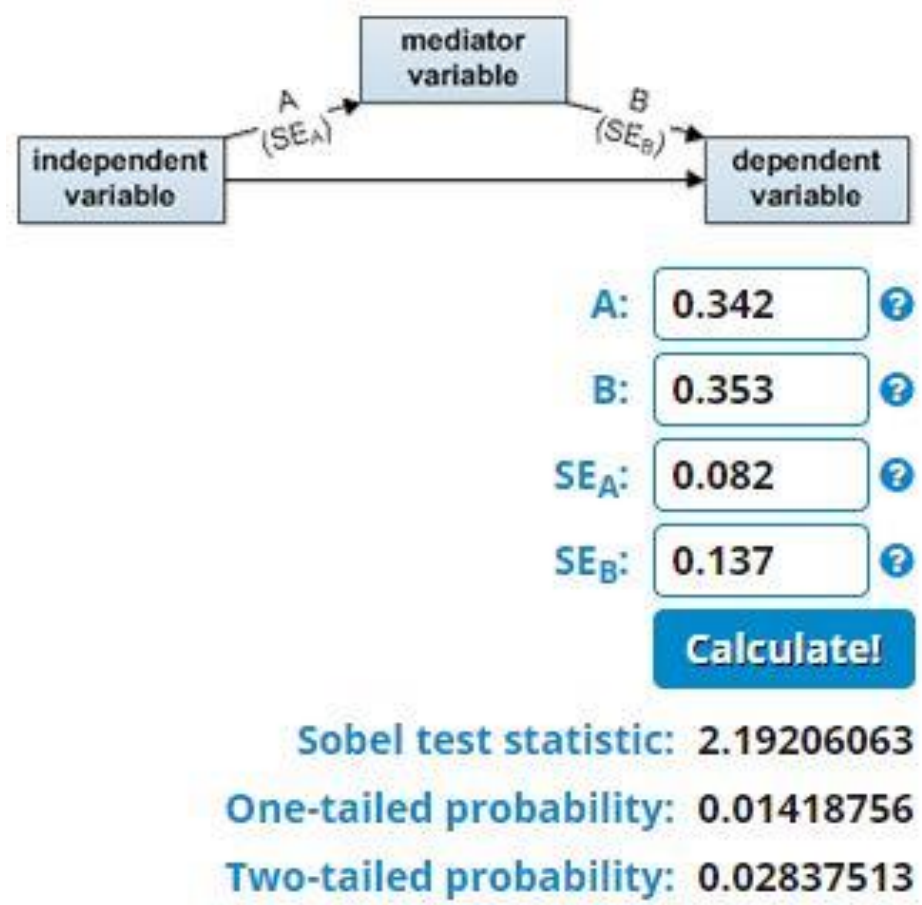

Gambar 2

Pengaruh Tidak Langsung Information Quality

Sumber : Data Primer Diolah, 2020

Dari hasil perhitungan sobel test di atas mendapatkan nilai sobel test sebesar 2,192, karena nilai sobel test yang diperoleh sebesar 2,192>1,9847 maka dapat diambil kesimpulan bahwa Trust mampu menjadi variabel mediasi antara Information Quality dan Online Purchase Intention.

\section{B. Pembahasan}

Responden dalam penelitian ini merupakan mahasiswa aktif di Universitas Sarjanawiyata Tamansiswa pengguna aplikasi Shopee. Seluruh responden merupakan pengguna aplikasi Shopee yang menunjukkan bahwa mahasiswa merupakan salah satu kalangan yang cukup konsumtif.

Hasil analisis data menunjukukan bahwa dari 100 orang responden didominasi oleh responden yang berjenis kelamin laki-laki sebanyak 52 orang dengan presentase sebesar $52 \%$. Peneliti berpendapat bahwa mayoritas responden berjenis kelamin lakilaki menunjukkan bahwa laki-laki ternyata tidak kalah konsumtif dari pada perempuan. Sedangkan dari segi usia, mayoritas responden berada pada usia 21-25 tahun sebanyak 66 orang dengan persentase sebesar $66 \%$. Peneliti berpendapat bahwa 
mayoritas responden merupakan yang berusia 21-25 tahun dikarenakan pada usia tersebut merupakan usia dimana seseorang sedang asik mengikuti tren sehingga mendorong sifat konsumtif.

Untuk hasil pengujian hipotesis, dari hasil analisis yang telah dilakukan, pengaruh Perceived Security, Information Quality terhadap Online Purchase Intention melalui Trust dengan uji $\mathrm{T}$.

\section{Pengaruh Perceived Security Terhadap Trust}

Perceived Security juga berpengaruh terhadap Trust pada aplikasi Shopee, karena Shopee menjamin keamanan tranksaksi yang tinggi, sehingga dapat meningkatkan kepercayaan responden terhadap Shopee. Hal ini sesuai dengan salah satu indikator perceived security yaitu keamanan informasi keuangan. Senada dengan penelitian yang dilakukan oleh Escobar-Rodríguez \& BonsónFernández, (2017), Perceived Security berpengaruh terhadap Trust pada fashion ecommerce di Spanyol.

\section{Pengaruh Information Quality terhadap Trust}

Information Quality berpengaruh terhadap Trust pada aplikasi Shopee, hal ini didukung dengan penelitian yang dilakukan oleh Escobar-Rodríguez \& Bonsón-Fernández, (2017). Seperti yang disebutkan pada indikator ketiga variabel Information Quality pada penelitian ini yaitu informasi yang lengkap. Kepercayaan responden terhadap Shopee akan meningkat bila informasi yang diterima dinilai akurat, relevan, dan lengkap.

\section{Pengaruh Perceived Security terhadap Online Purchase Intention}

Perceived Security berpengaruh terhadap Online Purchase Intention senada dengan penelitian oleh T, Setyawati. Y, Djoko Suseno. Rahayu, (2017). Keamanan ada hal paling penting dalam bertransaksi secara online. Dengan tingkat keamanan dalam bertransaksi dan keamanan akan profil konsumen yang yang diberikan Shopee, maka secara otomatis akan menimbulkan niat beli responden pada aplikasi Shopee.

\section{Pengaruh Information Quality terhadap Online Purchase Intention}

Information Quality secara langsung berpengaruh terhadap Online Purchase Intention pada aplikasi Shopee, selaras dengan penelitian oleh (Atika et al., 2017), hal ini karena Shopee berhasil menyediakan segala informasi yang dibutuhkan konsumen. Dengan tersedianya informasi yang jelas tentang produk, penilaian kualitas dan seputar transaksi maka akan menciptakan niat beli pada responden terhadap produk di aplikasi Shopee.

\section{Pengaruh Trust terhadap Online Purchase Intention}

Trust berpengaruh terhadap Online Purchase Intention pada aplikasi Shopee mendukung penelitian yang dilakukan oleh Escobar-Rodríguez \& BonsónFernández, (2017) karena dengan tingginya kepercayaan responden terhadap Shopee, maka akan meningkatkan niat beli konsumen terhadap produk-produk yang tersedia di aplikasi Shopee. 


\section{Kesimpulan}

Berdasarkan hasil penelitian ini, maka diperoleh kesimpulan sebagai berikut : 1) Variabel Perceived Security berpengaruh signifikan terhadap variabel Trust pada aplikasi Shopee, yang berarti Perceived Security merupakan faktor penting yang mempengaruhi Trust pada aplikasi Shopee. 2) Variabel Information Quality berpengaruh signifikan terhadap variabel Trust pada aplikasi Shopee, yang berarti Information Quality merupakan faktor penting yang mempengaruhi Trust pada aplikasi Shopee. 3) Variabel Perceived Security berpengaruh signifikan terhadap variabel Online Purchase Intention pada aplikasi Shopee, yang berarti Perceived Security merupakan factor penting yang mempengaruhi Online Purchase Intention pada aplikasi Shopee. 4) Variabel Information Quality berpengaruh signifikan terhadap variabel Online Purchase Intention pada aplikasi Shopee, yang berarti Information Quality merupakan faktor penting yang mempengaruhi Online Purchase Intention pada aplikasi Shopee. 5) Variabel Trust berpengaruh signifikan terhadap variabel Online Purchase Intention pada aplikasi Shopee, yang berarti Trust merupakan faktor penting yang mempengaruhi Online Purchase Intention pada aplikasi Shopee. 6) Shopee berhasil menjadi raja $e$ commerce di Indonesia sejak kuartal 4 tahun 2019, namun menurunnya jumlah pengunjung Shopee pada kuartal 1 tahun 2020 dikarenakan tingginya persaingan dengan e-commerce lain atau menurunnya niat beli pada konsumen. 
Selfi Dayanti, Ida Bagus Nyoman Udayana, Bernadetta Diansepti Maharani

\section{BIBLIOGRAFI}

Alwafi, F., \& Magnadi, R. H. (2016). Pengaruh persepsi keamanan, kemudahan bertransaksi, kepercayaan terhadap toko dan pengalaman berbelanja terhadap minat beli secara online pada situs jual beli tokopedia. com. Diponegoro Journal of Management, 5 (2), 134-148. Google Scholar

Atika, Kusumawati, A., \& Iqbal, M. (2017). The Effect Of Electronic Word Of Mouth, Message Source Credibility, Information Quality On Brand Image And Purchase Intention. Ekuitas (Jurnal Ekonomi Dan Keuangan), 20 (1), 94. Google Scholar

Berlilana, B., Suyanto, M., \& Luthfi, E. T. (2017). Pengaruh Penerapan Kualitas Kegunaan, Kualitas Informasi dan Kualitas Interaksi Website Terhadap

Kepercayaan Konsumen Hotel Di Kabupaten Banyumas. Jurnal IT CIDA, 3 (2), 119. Google Scholar

Dewi, S. A. N. T., \& Dwirandra, A. (2013). Pengaruh Dukungan Manajemen Puncak, Kualitas Sistem, Kualitas Informasi, Pengguna Aktual Dan Kepuasan Pengguna Terhadap Implementasi Sistem Informasi Keuangan Daerah Di Kota Denpasar. EJurnal Akuntansi Universitas Udayana, 1 (4), 196-214. Google Scholar

Escobar-Rodríguez, T., \& Bonsón-Fernández, R. (2017). Analysing online purchase intention in Spain: fashion e-commerce. Information Systems and E-Business Management, 15 (3), 599-622. Google Scholar

Fahmi, Z., \& Evanita, S. (2019). Pengaruh Iklan dan Perceived Security terhadap Minat Transaksi Pebayaran Berbasis e-Payment dengan Sikap sebagai Variabel Intervening pada Masyarakat di Kota Padang. Jurnal Kajian Manajemen Dan Wirausaha, 01 (02), 83-96. Google Scholar

Ferdiansyah, G., \& Rahayu, A. (2016). Pengaruh Kualitas Informasi Terhadap Keputusan Pembelian Secara Online Yang Dimediasi Oleh Kepercayaan Konsumen (Survei Pada Pengguna E-Commerce Di Indonesia). Journal of Business Management Education (JBME), 2(2), 17-20. Google Scholar

Halim, M. P. (2015). Kajian Indikator Kepercayaan Konsumen Akan Online Review Pada Proses Keputusan Booking Hotel Secara Online. Akademika, 13 (1), 21-27. Google Scholar

Idris, C. A. (2017). Analisis pengaruh kualitas online Word-Of-Mouth dan keamanan terhadap minat beli dengan kepercayaan sebagai variabel intervening pada pembelian produk fashion di situs zalora Indonesia di semarang. Diponegoro Journal of Management, 6 (3), 1-11. Google Scholar

Parastanti, G. P., Kumadji, S., \& Hidayat, K. (2014). Pengaruh Prior Online Purchase Experience Terhadap Trust Dan Online Repurchase Intention (Survey pada Pelanggan Zalora Indonesia Melalui Website www.zalora.co.id). Jurnal Administrasi Bisnis S1 Universitas Brawijaya, 16 (1). Google Scholar 
Rizki, K., Astuti, E., \& Susilo, H. (2015). Pengaruh Kemudahan Dan Kualitas Informasi Terhadap Minat Dan Keputusan Pembelian Secara Online (Survei Pada Konsumen www.ardiansmx.com). Administrasi Bisnis, 28 (1), 56-63. Google Scholar

Semuel, H., \& Setiawan, K. Y. (2018). Promosi Melalui Sosial Media, Brand Awareness, Purchase Intention Pada Produk Sepatu Olahraga. Manajemen Pemasaran, 12 (1), 47-52. Google Scholar

Semuel, H., \& Setiawan, K. Y. (2018). Promosi Melalui Sosial Media, Brand Awareness, Purchase Intention Pada Produk Sepatu Olahraga. Manajemen Pemasaran, 12 (1), 47-52. Google Scholar

T, Setyawati. Y, Djoko Suseno. Rahayu, T. (2017). Pengaruh Keamanan Dan Kepercayaan Terhadap Niat Beli Produk Online Shop Dengan Norma Subjektif Sebagai Variabel Moderasi. Jurnal Manajemen Sumber Daya Manusia, 191-203. Google Scholar

Widarsono, A. (2007). Pengaruh Kualitas Informasi Manajemen Terhadap Kinerja Manajerial (Survey pada perusahaan go-publik di Jawa Barat). Jurnal Akuntansi FE Unsil, 2 (2), 286-299. Google Scholar

\section{Copyright holder:}

Selfi Dayanti, Ida Bagus Nyoman Udayana, Bernadetta Diansepti Maharani (2021)

First publication right:

Jurnal Syntax Admiration

This article is licensed under:

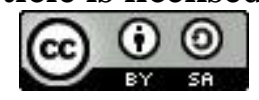

